\title{
Subcutaneous Emphysema without Pneumothorax: A Rare Complication following Ventriculoperitoneal Shunt Surgery
}

\author{
Bhagya R. Jena ${ }^{1}$ Indu Kapoor ${ }^{1}$ Mihir P. Pandia ${ }^{1}$ \\ ${ }^{1}$ Department of Neuroanaesthesiology and Critical Care, \\ Neurosciences Centre, All India Institute of Medical Sciences, \\ New Delhi, India
}

J Neuroanaesthesiol Crit Care:2021;8:71-71

Subcutaneous emphysema is a known complication associated with ventriculoperitoneal shunt surgery. Awareness about this potential complication can help in prevention of its occurrence as well as early diagnosis and timely management.

Subcutaneous emphysema (SE) with or without pneumothorax is a rare complication of ventriculoperitoneal (VP) shunt surgery, which every anesthesiologist should be aware of. Awareness about this potential complication can help in the prevention of its occurrence as well as early diagnosis and timely management. A written informed consent was taken from patient for publication. We report a case of a 25 -year-old male patient diagnosed with left cerebellopontine angle tumor with hydrocephalus. The patient was posted for right-side VP shunt surgery under general anesthesia prior to definitive tumor resection. After attaching all routine monitors, anesthesia was induced with fentanyl $2 \mu \mathrm{g} / \mathrm{kg}$, propofol $2 \mathrm{mg} / \mathrm{kg}$, and rocuronium $0.6 \mathrm{mg} / \mathrm{kg}$. His trachea was intubated with 8.5 cuffed polyvinylchloride endotracheal tube. Intraoperative course remained uneventful. At the end of surgery, a small swelling was noticed on the right side of the neck. On palpation, we could feel crackling or popping sensation under the skin. Subsequently, crepitus all over the chest on the right side was noticed. Keeping in mind the association of pneumothorax with SE, the patient was shifted without reversal from anesthesia with endotracheal tube in situ to intensive care unit for further management. Airway pressures remained in normal range throughout (13-15 cmH2O). An urgent chest X-ray was done that did not show any evidence of pneumothorax. Patient was gradually weaned off and was extubated next day after confirming repeat chest X-ray that was again normal. The neck swelling and emphysema subsided by the third day.

Though benign, SE can cause respiratory distress, anxiety, airway compromise, air embolism, and sometimes even

\section{Published online}

May 9, 2020
DOI https://doi.org/

$10.1055 / \mathrm{s}-0039-1687816$

ISSN 2348-0548.
Address for correspondence Indu Kapoor, MD, Department of Neuroanaesthesiology and Critical Care, Neurosciences Centre, All India Institute of Medical Sciences, New Delhi 110029, India (e-mail: dr.indu.me@gmail.com).

death. ${ }^{1}$ Other than VP shunt surgeries, SE has been reported with other procedures such as percutaneous tracheostomy, chest drain insertion, and brachial plexus block. ${ }^{2-4}$ Often SE is found to be associated with underlying pneumothorax. However, if the pleural puncture is small, it may get sealed off before it becomes symptomatic. ${ }^{4}$ In such cases, a pneumothorax may be localized rather than spreading throughout the pleural space. ${ }^{5}$ In our case, sole SE occurred without pneumothorax following VP shunt surgery, which is a common procedure done in neurosurgical patients. Through our case report, we would like to remind clinicians about this possible rare complication during VP shunt surgery, which can simply be avoided by proper surgical steps followed by neurosurgeon while maintaining the depth of anesthesia along with complete neuromuscular blockade provided by the anesthesiologist.

\section{Conflict of Interest}

None declared.

\section{References}

1 Abu-Omar Y, Catarino PA. Progressive subcutaneous emphysema and respiratory arrest. J R Soc Med 2002;95(2):90-91

2 Kaylie DM, Wax MK. Massive subcutaneous emphysema following percutaneous tracheostomy. Am J Otolaryngol 2002;23(5):300-302

3 Ture P, Kurdi M, Shaikh S, Kallapur B. An unusual case of subcutaneous emphysema without pneumothorax following brachial plexus block. J Anaesthesiol Clin Pharmacol 2016; 32(1):117-118

4 KumariA,GuptaR,BhardwajA,MadanD.Delayed pneumothorax after supraclavicular block. J Anaesthesiol Clin Pharmacol 2011;27(1):121-122

5 Paramasivam E, Bodenham A. Air leaks, pneumothorax, and chest drains. Contin Educ Anaesth Crit Care Pain 2008;8(6): 204-209
C2020. Indian Society of Neuroanaesthesiology and Critical Care. This is an open access article published by Thieme under the terms of the Creative Commons Attribution-NonDerivative-NonCommercial-License, permitting copying and reproduction so long as the original work is given appropriate credit. Contents may not be used for commercial purposes, or adapted, remixed, transformed or built upon. (https://creativecommons.org/licenses/by-nc-nd/4.0/).

Thieme Medical and Scientific Publishers Pvt. Ltd. A-12, 2nd Floor, Sector 2, Noida-201301 UP, India 